\title{
Factors influencing e-health implementation by medical doctors in public hospitals in Zimbabwe
}

\begin{tabular}{|c|c|}
\hline \multicolumn{2}{|c|}{$\begin{array}{l}\text { Authors: } \\
\text { Samuel S. Furusa }{ }^{1} \text { () } \\
\text { Alfred Coleman }{ }^{2}\end{array}$} \\
\hline \multicolumn{2}{|c|}{$\begin{array}{l}{ }^{1} \text { Department of Computer } \\
\text { Science and Information } \\
\text { Systems, Faculty of Science } \\
\text { and Technology, Midlands } \\
\text { State University, Zimbabwe }\end{array}$} \\
\hline \multicolumn{2}{|c|}{$\begin{array}{l}{ }^{2} \text { School of Computing, } \\
\text { College of Science, } \\
\text { Engineering and Technology, } \\
\text { University of South Africa, } \\
\text { South Africa }\end{array}$} \\
\hline \multicolumn{2}{|c|}{$\begin{array}{l}\text { Corresponding author: } \\
\text { Samuel Furusa, } \\
\text { mubaiwa40@gmail.com }\end{array}$} \\
\hline \multicolumn{2}{|c|}{$\begin{array}{l}\text { Received: } 15 \text { Nov. } 2017 \\
\text { Accepted: } 19 \text { Mar. } 2018 \\
\text { Published: } 14 \text { June } 2018\end{array}$} \\
\hline \multicolumn{2}{|c|}{$\begin{array}{l}\text { How to cite this article: } \\
\text { Furusa, S.S. \& Coleman, A., } \\
\text { 2018, 'Factors influencing } \\
\text { e-health implementation by } \\
\text { medical doctors in public } \\
\text { hospitals in Zimbabwe', } \\
\text { South African Journal of } \\
\text { Information Management } \\
\text { 20(1), a928. https://doi.org/ } \\
\text { 10.4102/sajim.v20i1.928 }\end{array}$} \\
\hline \multicolumn{2}{|c|}{$\begin{array}{l}\text { Copyright: } \\
\text { @ 2018. The Authors. } \\
\text { Licensee: AOSIS. This wc } \\
\text { is licensed under the } \\
\text { Creative Commons } \\
\text { Attribution License. }\end{array}$} \\
\hline \multicolumn{2}{|l|}{ Read online: } \\
\hline 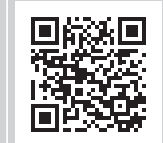 & $\begin{array}{l}\text { Scan this QR } \\
\text { code with your } \\
\text { smart phone or } \\
\text { mobile device } \\
\text { to read online. }\end{array}$ \\
\hline
\end{tabular}

Background: Improving access to health care services in both developed and developing countries through information communication technology (ICT) has been getting particular attention from government, medical researchers and practitioners. This has seen many governments proposing the implementation of healthcare systems that are centred on technology, while researchers and practitioners have been arguing for policies that promote the use of technology in healthcare provision.

Objective: The main objective of this study was to determine the factors influencing implementation of e-health by medical doctors in public hospitals in Zimbabwe.

Methods: The study was guided by a qualitative research in conjunction with multiple-case studies. Qualitative data were collected using 20 semi-structured interviews from selected hospitals concerning the implementation of e-health by medical doctors in public hospitals. Hospitals were selected using random sampling, while purposive sampling was used to select the 20 doctors. In addition, the researcher conducted direct observations at five hospitals. Furthermore, data concerning policy issues in Zimbabwe's e-health were collected using document review process. Data from the interviews were analysed using data-driven thematic coding. This solo approach was conducted because the researcher intended to reveal e-health influencing factors that could not be revealed by related literature.

Results: This study reveals that the implementation of e-health by medical doctors in public hospitals in Zimbabwe is influenced by both internal and external factors. Internal factors include ICT infrastructure and e-health technologies, ICT skills and knowledge, technical support, security concerns, lack of basic medical facilities, demographic factors such as age and doctor-patient relationship. External factors are health policy, funding and bureaucracy.

Conclusion: The idea of e-health is relatively new to healthcare centres in Zimbabwe. Its application has not been sufficiently addressed. The study shows that the success of an e-health system depends on internal and external factors. There is a great potential for implementing e-health in Zimbabwe if these factors are taken into consideration. Otherwise, Zimbabwe will continue to lag behind in the implementation of e-health systems in public hospitals.

\section{Introduction}

The use of technology in providing health services has been a major priority for many developed and developing countries (Osunyomi \& Grobbelaar 2013). Technology has become an enabling tool in health service delivery. In fact, the use of technology in the health sector has led to the implementation of electronic health (e-health) services. Many developed nations have made enormous investments in e-health systems and the developing states are also making efforts to implement these systems (Busagala \& Kawono 2013; Nielsen 2016; Sementilli, Auria \& Mori 2007; Stroetmann, Artmann \& Stroetmann 2013). Technologically, e-health is one of the vehicles which health service providers are expected to implement in order to provide quality health to all, as enshrined in many e-government and e-health policy documents. Thus, through e-health systems, equitable, affordable and convenient health services will be delivered to all citizens.

\section{Background to the study}

Improving the health of people is the fundamental objective of e-health systems (Crock 2016). e-Health systems are patient-centric and involve the use of modern information systems and technologies to integrate and coordinate the delivery of healthcare to ensure improved patient outcomes, greater efficiencies of delivery, higher levels of transparency and improved ease of access (http:/ / www.ehealthireland.ie). Examples of standard e-health systems include electronic prescribing (e-prescribing), whereby patients can order repeat prescriptions online, do online 
patient scheduling and referrals and also use tele-healthcare systems, whereby patients with, for example, diabetes or heart failure can manage their own healthcare from the home environment. e-Health systems also include newer technologies such as ambient assisted living (AAL) systems, robotic surgical systems and body-worn sensor devices (http://www.ehealthireland.ie).

In an ever more digital world, governments globally are recognising the prospective benefits of e-health to harness technology and health services, thereby improving the health system of a country. The introduction of e-health paradigm has been received as an important element in healthcare systems (Lam et al. 2016). e-Health is one of the fastest growing sectors in the overall healthcare domain and can be used at the local, national, regional and global levels as a resourceful means to promote and strengthen health systems and health information (Farzianpour, Amirian \& Byravan 2015; Juma et al. 2012).

e-Health has been a priority for the World Health Organization (WHO) since 2005, when the World Health Assembly resolution WHA58.28 was adopted (Qureshi \& Shah 2013). The migration to e-health is necessary to provide quality health care because it allows for seamless flow of health information among various entities. Research on e-health has revealed that e-health can be one solution to give better access to healthcare services for patients (Sementilli et al. 2007). In addition, the system enables healthcare professionals to increase care quality. Thus, the demand for high-quality and equitable distribution of healthcare has been the major motivation for both government and healthcare providers to concentrate on e-health as an approach to overcome various challenges faced by health institutions.

e-Health implementation has played a substantial role in shaping health care systems in the 21st century (Qureshi \& Shah 2013). It has gained momentum in areas such as health portals, electronic health records (EHR), electronic medical records (EMR), personal health records (PHR), and health information systems (HIS), telemedicine, e-prescription, remote patient monitoring (RPM) and diagnosis (Busagala \& Kawono 2013). e-Health is gradually eliminating paperbased health and health care. Many countries are optimistic that e-health can also lower the costs and expand the access to health. Thus, e-health is becoming a reality in both developed and developing countries and holds great promise in improving global access to healthcare services and health informatics.

Studies regarding e-health and its successful implementation have been conducted in both developed and developing countries (Catwell \& Sheikh 2009; Lam et al. 2016; Moerman, Houwelingen \& Kort 2014; Nielsen 2016; Schweitzer \& Synowiec 2010; Sementilli et al. 2007; Stroetmann et al. 2013). Regardless of well-defined benefits of e-health, its implementation remains low in developing countries, especially in public hospitals with little research that explains this phenomenon (Juma et al. 2012; Mugo 2014).
One notable observation is that countries use unique approaches towards the implementation of e-health (Mugo 2014). This explains why the implementation of e-health is not the same globally.

In spite of the distinctive approach towards e-health, the factors that influence the implementation of e-health seem to be both universal and contextual. According to Ross et al. (2016), several factors have been discovered as important variables in defining the successful implementation of e-health. Many developing countries are faced with lack of resources to equip health institutions with modern technologies (Mugo 2014), poor policies that fail to address short-term and long-term needs (Busagala \& Kawono 2013), limited budgets allocated to the health sector (UNICEF 2016) and lack of information communication technology (ICT) skills and knowledge (Lam et al. 2016). As a result, the level of implementation of e-health has been low. Hence, this study was motivated by the need to improve the implementation of e-health systems to include EMR and tele-healthcare, telemedicine systems and diagnostic-related group (DRG) systems. These systems are central to the need of both general practitioners and medical specialists in the provision of e-health. Thus, the researcher performed rigorous research on the factors that influence the implementation of e-health by doctors in public hospitals in Zimbabwe.

\section{Concept of e-health}

The concept of e-health operates in the confluence of medical informatics and public health. Overall, it aims to deliver health services and information through the Internet and related technologies both at the local site and at a distance (Mugo 2014). e-Health should be viewed as both the critical infrastructure that forms the foundation of information exchange among the users of healthcare systems and as a means of improved health outcomes for all. The term 'e-health' has been defined in various forms. e-Health has been defined as an combination of healthcare system and ICT to enable better health and healthcare (Busagala \& Kawono 2013). According to Mugo (2014), e-health involves a wide range of actions that use electronic means to provide healthrelated information, resources and services. In simple terms, it is defined by WHO (2016a) as the use of ICT for health. Qureshi and Shah (2013) describe e-health as any electronic exchange of health information within the healthcare sector. The notion of e-health thus covers all aspects of health through the use of technology to provide new methods for utilising and improving health services. For example, doctors can provide remote treatment to patients using e-health, while other medical professionals can use the same system to track diseases and other epidemic outbreaks in different environments (Moerman et al. 2014).

Furthermore, e-health can be used to facilitate awareness campaigns on health matters and promote health initiatives. It can bring a paradigm swing in traditional healthcare systems by minimising medical errors, promoting healthcare quality, reducing healthcare costs and empowering patients 
to take care of their medical needs (Catwell \& Sheikh 2009). e-Health also enables patients and health care providers to interact virtually. This interaction is facilitated by mobile and web technologies for online bookings, remote monitoring devices that are capable of measuring physiological parameters and real-time patient consultations (Crock 2016). The value of e-health is in its capability to help lower costs in health sector, while delivering better care within a citizen-centred approach. Hence, there is general consensus that, when properly deployed and adopted by nurses and other healthcare professionals, e-health solutions can increase efficiency, enhance patient safety and care coordination, and optimise health outcomes (Busagala \& Kawono 2013; Mugo 2014).

\section{The global state of e-health}

The state of e-health worldwide is not the same because there is no universal approach in the implementation of e-health systems. In some developed countries, more than half of primary care physicians use EHR. These include Sweden, the Netherlands and Australia who have 90\%, 62\% and 55\%, usage respectively (Mugo 2014). In other developed countries, even though the diffusion of technology is high and the economy is stable, the adoption of e-health seems to be significantly lower. Only $1.2 \%$ of all hospitals and $2.6 \%$ of all clinics adopted EHR in Japan (Nzuki \& Mugo 2014), and in the United States, according to national electronic health records survey National Centre for Health Statistics (2015), the percentage of physicians using any EMR/EHR system varied by state, ranging from $54 \%$ in New Jersey to $89 \%$ in Massachusetts.

While the adoption of e-health systems has been low in some developed countries, the success of e-health adoption has also been low for developing countries, who are confronted with challenges of insufficient e-health infrastructure and lack of technical expertise and computer skills of staff (Lam et al. 2016). Consequently, the global state of e-health implies that the implementation of e-health systems does not solely depend on the availability of technology but on other factors such as technical support in medical institutions and poor experiences in ICT among health practitioners. Accordingly, factors that influence the implementation of e-health cannot be generalised, rather they need to be contextualised. Hence, rigorous research is considered necessary to identify these factors in different contexts.

\section{Theoretical framework}

Information technology (IT) acceptance is a process which is influenced by complex external and internal factors (Alberta Health Services 2010; Ross et al. 2016). Several contending theoretical models have been proposed and used to study the determinants of acceptance and use of new IT (Zhang et al. 2015). However, in the context of e-health, Rogers (1995) diffusion of innovation (DOI) theory has been widely used to conceptualise technology adoption (Caldwell \& Kleppe 2010;
Raingruber 2014). The theory seeks to understand the manner in which innovations spread within and between communities. As Rogers explains, innovation is perceived as an idea, process or a technology that is new or unfamiliar to individuals within a particular area or context, while diffusion is the process by which information about the innovation flows from one person to another over time within the social system (WHO 2016b). Many studies have demonstrated that Rogers' innovation theory is an appropriate instrument to understand technology adoption in the context of e-health initiatives (Adams, Tranfield \& Denyer 2011; Lien \& Jiang 2017; Raingruber 2014; Rissanen 2014; Tucker 2009; WHO 2016b). They found that the five constructs of DOI, which are relative advantage, trial ability, compatibility, complexity and observability, influenced the manner in which medical practitioners accepted new technology. It has been observed that medical personnel accept technology that is compatible with their work and processes (Lien \& Jiang 2017). Furthermore, new technology should give relative advantage over the current practice, in this case traditional health approach. Moreover, it should be tried and its impact observed before use and above all it should have low complexity through a user-friendly interface (Zhang et al. 2015). The theory has been chosen because e-health is new and unfamiliar to many medical practitioners in Zimbabwe because it is in its pilot phase. In addition, there has been low level of diffusion of e-health systems among the public hospitals in Zimbabwe. Hence, this theory was used to study the factors influencing e-health implementation by medical doctors in public hospitals in Zimbabwe.

\section{Methodology}

The research on the factors influencing e-health implementation in public hospitals in Zimbabwe was guided by a qualitative research. This was done through a multiple-case study approach. The target population comprised all public hospitals and all medical doctors, both general practitioners and specialists from public hospitals in Zimbabwe. Field research was carried out through semi-structured interviews to collect data from selected medical doctors concerning the implementation of e-health in various public hospitals. These hospitals were suitable for selection in this study because they handle a majority of citizens in Zimbabwe and they are the highest referral hospitals in the country. Data from these hospitals enabled the researcher to collect rich cases useful to the study, resulting in an in-depth account of the phenomena pertaining to factors influencing e-health implementation in hospitals. Using random sampling, the researcher selected three central hospitals and seven provincial hospitals from the public health sector. Purposive sampling was used to select medical doctors who were both specialists and general practitioners as a true representative of the target population of the study. A total of 20 medical doctors from both central and provincial hospitals in Zimbabwe took part in this study. The researcher targeted the medical doctors who have either used an e-health system at the public hospital or were using technology to perform their duties as medical practitioners. Thus, most of the interviewed doctors have 
used telemedicine systems, EHR and the district hospital information system (DHIS).

Therefore, the findings of this study are based on the medical doctors' experiences on the use of technology in healthcare delivery in public hospitals in Zimbabwe. The participants were categorised into specialists and general practitioners. The major issues that were covered in the interviews included the current trends of e-health in Zimbabwe and the factors affecting the adoption of technology in healthcare provision in public health institutions. The researcher also carried out direct observations on five public hospitals to determine the current state of e-health systems and e-health infrastructure. In addition, the researcher performed document review on the health policies in Zimbabwe to establish if these policies were aligned with the e-health strategy of the country.

\section{Data analysis}

Textual data from the interviews were analysed using a single approach, that is, data-driven thematic coding (Kawulich 2004). This solo approach to data analysis was conducted because the researcher intended to reveal e-health influencing factors that could not be revealed by related literature. In addition, the researcher was also aware that the use of theoretical thematic coding could conceal the strength of the data to bring out new insights. Hence, the coding technique was used to establish factors that are not universal in e-health implementation.

\section{e-Health in Zimbabwe}

Despite the advancements in e-health in other countries, Zimbabwe has little activity where quality healthcare is inaccessible to most of the population in the country (Chikuni 2016). Consequently, several technology introductions in Zimbabwe are mainly customised to each hospital and do not communicate with each other. Zimbabwe has very few hospitals that have acted as the frontier for e-health systems. Ministry of Health and Child Welfare (MoHCC) Zimbabwe and hospital management are enabling e-health by the deployment of the DHIS and Systems, Applications and Products (SAP) healthcare solutions in government hospitals. The DHIS was rolled out in 2010 in all hospitals in Zimbabwe, and the platform is mainly being used for recording the details of patients, disease surveillance, reporting and analysis. The platform is meant for administrative healthcare authorities and HIS personnel. The platform does take into consideration the module for clinical care. The SAP healthcare was deployed at one of the central hospitals in Harare and is mainly used for maintaining patient records. The records include the demographics and billing of patients and maintenance of clinical records. The records are provided in real-time which improves healthcare collaboration.

Furthermore, the ministry also launched the pilot EHR systems in Uzumba-Maramba-Pfungwe District, Mashonaland East, which can be operationalised from the lowest level in rural clinics capturing all the patient data. The pilot project is intended to be spread across all public health facilities in the country (Kaerasora 2017). In addition, the Ministry of Health and the Ministry of ICT have been successfully conducting a joint telemedicine pilot project in Manicaland province in 2016. The system is now connected to the telemedicine system at Parirenyatwa group of hospitals, which was launched in 2015.

\section{Factors that influence e-health implementation in Zimbabwe}

This section presents the factors influencing implementation of e-health by medical doctors in public hospitals in Zimbabwe. The main themes that emerged from the data were categorised as global and local themes. Global themes were classified as internal and external factors, while the local themes represented the sub-themes under each global theme. The local themes are presented and discussed below under appropriate global themes.

\section{Internal factors}

\section{Information communication technology infrastructure and e-health technologies}

The health sector is one of the significant sectors which require the use of ICT to improve the quality of healthcare delivery to all citizens. Particularly, the application of e-health is dependent on various technologies and ICT infrastructure. This study found out that there is a lack of ICT infrastructure that supports e-health systems. Currently, a number of hospitals in Zimbabwe do not have enough technologies in place for e-health. The present ICT tools are meant for administration and procurement functions. Many doctors complained about the lack of adequate infrastructure for e-health to be implemented. One participant stressed that:

\begin{tabular}{|c|c|c|}
\hline Global themes & Local themes & $\begin{array}{l}\text { Theme derivation/source of } \\
\text { information }\end{array}$ \\
\hline \multirow[t]{8}{*}{ Internal factors } & $\begin{array}{l}\text { ICT infrastructure and } \\
\text { e-health technologies }\end{array}$ & $\begin{array}{l}\text { A description of information relating } \\
\text { to technology }\end{array}$ \\
\hline & ICT skills and knowledge & $\begin{array}{l}\text { A description of information relating } \\
\text { to ICT and skills }\end{array}$ \\
\hline & Technical support & $\begin{array}{l}\text { A description of information relating } \\
\text { to IT department }\end{array}$ \\
\hline & Security concerns & $\begin{array}{l}\text { A description of information relating } \\
\text { to privacy of patient information }\end{array}$ \\
\hline & $\begin{array}{l}\text { Doctor-patient } \\
\text { relationship }\end{array}$ & $\begin{array}{l}\text { A description of information relating } \\
\text { to interaction between doctor and } \\
\text { patients }\end{array}$ \\
\hline & $\begin{array}{l}\text { Lack of basic medical } \\
\text { facilities }\end{array}$ & $\begin{array}{l}\text { A description of information relating } \\
\text { to medical equipment }\end{array}$ \\
\hline & $\begin{array}{l}\text { Demographic factors } \\
\text { such as age }\end{array}$ & $\begin{array}{l}\text { A description of information relating } \\
\text { to old and young medical doctors }\end{array}$ \\
\hline & Resistance to change & $\begin{array}{l}\text { A description of information relating } \\
\text { to change in work process and } \\
\text { procedures }\end{array}$ \\
\hline \multirow[t]{3}{*}{ External factors } & Health policy & $\begin{array}{l}\text { A description of information pointing } \\
\text { to policy issues }\end{array}$ \\
\hline & Funding & $\begin{array}{l}\text { A description of information pointing } \\
\text { to money, funds and budget }\end{array}$ \\
\hline & Bureaucracy & $\begin{array}{l}\text { A description of information relating } \\
\text { to systems authority }\end{array}$ \\
\hline
\end{tabular}

IT, information technology; ICT, information communication technology. 
'There is no infrastructure to support e-health usage at this hospital. ... A lot of technologies such as computers, mobile and monitoring devices are required to implement e-health. This is one of the major challenges being faced by hospitals where the infrastructure to support the e-health systems are not available.' (Doctor: 6)

Similarly, another participant from a different hospital commented:

'Without the required infrastructure, a hospital is rendered incapacitated to implement the e-health systems for the betterment of the health service delivery.' (Doctor: 8 )

Again, another participant commented:

'The major setback in the use of e-health is the reliance of personal gadgets for some of the hospitals which have e-health projects. Limited ICT tools have been set aside for the medical departments ... you find out that the HR and procurement departments have better technologies than us here. As a result, most of our tasks are done manually.' (Doctor: 12)

Apparently, the comments made by the doctors in various hospitals suggest that e-health has failed to be implemented in hospitals owing to the lack of infrastructure. Like any other electronic system, e-health also requires the use of different technologies. e-Health infrastructure pertinently affects adoption of e-health (Kundi et al. 2013). According to Kundi et al. (2013), infrastructural issues are dominating the research on e-projects in all organisations including in the health sector (Qureshi and Shah 2013). e-Health infrastructure is seen to be a key factor. This becomes more critical in the background of a developing country like Zimbabwe. Hospitals in Zimbabwe lack appropriate technologies, computer systems/utilities that are relevant to improve healthcare services. In most cases, procurement departments are well equipped in ICT infrastructure than clinicians. This was also noted by the researcher during observations. Data from observations showed that the majority of public hospitals in Zimbabwe have limited ICT and e-health infrastructure.

In order to complement the inadequate e-health infrastructure, some doctors in Zimbabwe are now using personal gadgets such as smart phones. Despite this, the primary ICTs used in many public hospitals to manage healthcare still revolve around basic technology, pen and paper, simple database systems and human memory (Catwell \& Sheikh 2009). The use of such imperfect tools in healthcare should be a consideration in improving health services of the country. Thus, a number of components should all be made available to ensure that e-health systems can be implemented in hospitals.

\section{Information communication technology skills and knowledge}

e-Health infrastructure is not only expensive to establish but also requires ICT skills and knowledge for successful use of e-projects (Simbini 2013). Medical doctors with ICT skills will likely lead to the acceptance and the actual use of e-health in primary healthcare. This is because doctors with ICT skills and knowledge are able to appreciate the possible benefits of e-health in their work place. The lack of ICT skills and knowledge has been identified by participants as a contributing factor that influences the implementation of e-health in public hospitals. According to one participant:

'A number of doctors do not have adequate ICT skills and knowledge. Many of us are in the beginner's category of computer literacy. Such kind of levels has impeached the proper utilisation of e-health facilities in public hospitals. There is a need nowadays for every medical doctor to be conversant with technology that supports healthcare because in the medical field technology is now the way to go.' (Doctor: 1)

Similarly, the other participant notes that:

'Medical doctors do not take the time to properly become familiar with the available health technology and then train to use it. More so, there are no e-health training sessions being done at hospitals. Without these trainings the levels of ICT know how remains low.' (Doctor: 3 )

Inadequate ICT skills and knowledge among the medical doctors in the health sector in Zimbabwe explains the low adoption of e-health in public hospitals. Hence, they may not be able to embrace the use of e-health technologies. This evidence suggests the need for the MoHCC to educate doctors, enabling them to become techno-literate. Thus, educating and training medical professionals to adeptly make use of e-health is essential for adoption and implementation success (Olok, Yagos \& Ovuga 2015). Hence, ICT should be included in the curriculum of medical courses, and graduate doctors should receive e-health training sessions as in-service training.

Furthermore, the lack of ICT skills and knowledge among medical doctors makes the use of e-health complex. Information communication technology skills and knowledge are important in reducing the complexity of technology. According to the DOI theory, low level of complexity promotes adoption of technology because users can learn and use the technology (Öner \& Sertel 2015). Thus, it can be concluded that when promoting an innovation to the target population, it is important to ensure that the prospective users have adequate knowledge and skills.

\section{Technical support}

The implementation of an IT project also depends on the technical support from IT specialist. Technical support is important to maintain the system and keep it running. Technical support from IT departments was identified as another factor that complements the implementation of e-health systems. However, a number of participants indicated that they were not getting adequate technical support from IT personnel because of the unavailability of IT departments, the attitude of IT personnel or lack of expertise as highlighted below:

'Some [h]ospitals like this one do not even have an IT department rendering them a step behind in comprehending ICT tools.' (Doctor: 15) 
'You see IT support officers want to see the systems up and running always, when something goes wrong and you call them to come, they take time to respond.' (Doctor: 2)

'Our IT guys have limited computer skills; they are reluctant to learn new emerging technologies.' (Doctor: 7)

From these comments, it can be seen that technical support is apparently needed for the functioning of e-health systems. During the observation session, the researcher established that only central hospitals had small IT departments which employed between two and five IT support officers. The interviews and observations show that there is inadequate technical support for the majority hospitals. According to Ross et al. (2016), presence of technical support staff has been suggested as a strategy to reduce barriers related to disruptions to workflow, roles and responsibilities that e-health implementation may bring. Hence, hospitals should have ICT structures in place and IT officers should be conversant with technology used in healthcare centres.

\section{Security concerns}

Generally, ICTs are susceptible to security and privacy breaches which negatively impinge on their adoption in the health sector. This is because users of e-health want to be sure that the use of technology in healthcare will not result in unauthorised disclosure of information. Security of patient information is one of the key ethical values in the medical field. Data privacy, confidentiality and security concerns have been mentioned as among the factors influencing the adoption of e-health in Zimbabwe. Doctors had the following to say:

'The implementation of such a system may result in the violation of doctor-patient privacy. The anticipation is anyone with credentials can enter the system and access any medical records. This takes the information to anyone who wants it.' (Doctor: 11)

'While technology is comparatively important in the health sector, it can compromise data integrity of patients if e-health systems are hacked.' (Doctor: 18)

'What I can tell you is that with electronic systems information is never safe, it can be accessed through unauthorised means.' (Doctor: 16)

The implication here is that security of e-health data are of paramount importance if e-health is to gain confidence among healthcare stakeholders. The expectations of the stakeholders are that privacy of the e-health data should be on par with that of paper record systems. Previous research has also reported fears over a loss of autonomy (Dünnebeil et al. 2012), concerns about liability (Dehzad et al. 2014), concerns over patient privacy and security being compromised (Robinson 2008) and perceived threats to patient and health professional relationships (Kart, Miao \& Moser 2007) through the introduction of e-health systems, as barriers to use. The change to electronic platforms brings up some issues with privacy and security of patient data. Privacy and security are probably the most discussed issues within ICT ethics (Dinev et al. 2016). Therefore, in order to appreciate the full prospect of e-health, patients and providers must trust that the information being transmitted is confidential and protected. Thus, concerns about the privacy and security of e-health systems remain a barrier to broader use of e-health by medical doctors in public hospitals and may undermine the possible accomplishment of e-health if not addressed properly.

\section{Doctor-patient relationship}

The doctor-patient relationship is one of the most complex interpersonal relationships in healthcare. The doctors who participated in this study indicated that the use of e-health systems can either improve or abate the relationship between the doctor and the patient. Some doctors considered e-health as a tool to improve the relationship between the doctor and the patient through accessibility. These doctors had the following to say:

'I find technology useful in health sector because sometimes I give medical advice to patients using my mobile device in instances where visiting the doctor is not necessary. With this approach, I tell you doctors will be always in touch with the patients.' (Doctor: 20)

'I think with the advent of technology, my relationship with patients has improved. Patients can seek medical advice using mobile phones, for example, Skype or WhatsApp.' (Doctor: 9)

'When dealing with patients, think about the bottlenecks in accessing the medical service. I would strongly recommend any approach that enables me to have access to my patients $24 / 7$. This enables improved doctor-patient relationship and compliance with medications and recommendations.' (Doctor: 3)

However, other doctors were of the opinion that technology has a capability of weakening the doctor-patient relationship. During the interviews, the doctors gave the following opinions:

'Technology requires much attention; you have to concentrate [too] much on it. As a result, you lose attention to the patient.' (Doctor: 7).

'Technology diverts the doctor's attention from the main entity which is the patient.' (Doctor: 13)

Thus, doctors who participated in this study gave opposing views about the effect of technology on doctor-patient relationships. The doctor-patient relationship has been and remains a foundation of healthcare. In addition, doctors are also concerned about the possibility of e-health tools in altering their relationship with patients. According to Gerber and Eiser (2001), there is overwhelming evidence on doctors' concern regarding strained relationship with patients owing to e-health usage. Some doctors have disapproved of the use of e-health tools because they have a negative impact on the doctor-patient relationship (Ariens et al. 2013). e-Health tools have a possibility of shifting control of medical information. The impact of e-health use for health information has become a means of altering patients' roles. In many cases, e-health tools empower patients to have autonomy over their healthcare (Varsi 2016; WHO 2016a). Some doctors may feel challenged when patients bring information to consultations. 
As a result, some doctors have become unhappy about the application of technology such as telemedicine.

\section{Lack of basic medical facilities}

The unavailability of basic medical facilities has also served as a limitation to the utilisation of e-health facilities in Zimbabwe. Most hospitals complained about the unavailability of basic medical utensils to be used in treating patients. The following concerns were raised:

'Even if the system is to be put in place without required medical facilities it will remain not efficient. The challenge of efficiency will have that if the patient cannot be offered treatment adequate enough the system will still have many gaps and inconsistencies.' (Doctor: 4)

'How can we have advanced technology when the medical facilities do not have basic equipment? It doesn't sound.' (Doctor: 18)

These results show that Zimbabwe has limited advanced health institutions capable of carrying out multifaceted medical procedures using high-end technology. e-health systems without the appropriate equipment to use in patient treatment will still be unsuccessful. During observation, the researcher found out that hospitals have limited medical facilities, thereby making it difficult to prioritise technology ahead of basic facilities. Thus, the state of medical facilities has negatively impacted the utilisation of e-health in most hospitals.

\section{Demographic factors such as age}

By its very nature, age is a source of digital divide because the adoption and use of technology is correlated to age. During the interview, the participating doctors, especially the younger ones, expressed concern over the older doctors who went to medical school during the paper era. As one doctor observed:

'These senior doctors are troubled by the computers and their smart phones, an intensive electronic system might be one way to make their lives at work highly boring.' (Doctor: 14)

Similarly, another young doctor noted that:

'Old doctors lack the enthusiasm to work in an environment that is embedded in technology.' (Doctor: 16)

This shows that age is an important factor in the adoption and use of technology. There is greater ease of use of technology among young doctors than their older counterparts.

\section{Resistance to change}

The adoption of technology has the possibility of considerable change in work process, procedures and interaction. However, if the employees are not happy about the change, they are likely to resist it. In this case, the participants demonstrated some high degree of resistance to the adoption of e-health systems in public hospitals. The following sentiments were noted:
'We were trained to use short hand so if we were to use e-health it takes away my time with the patient. I would prefer conversion from voice to text.' (Doctor: 11)

Similarly, another participant had the following to say:

'Personally, I think e-health systems are more difficult to use than paper-based records.' (Doctor: 1 )

Medical doctors' uptake of ICT in their work procedures involves overcoming certain barriers, such as resistance to change. According to Bennani, Belalia and Oumlil (2008), medical personnel become resistant to the use of technology owing to the perceived negative impact on their workflow.

\section{External factors Health policy}

Developing a robust e-health system requires a suitable health policy. During the interviews, doctors identified problems with health policies that do not support the implementation of e-health systems in Zimbabwe. Accordingly, the absence of a clearly defined health policy may obstruct the implementation of e-health systems at all levels of healthcare. One doctor had the following to say:

'The lack of a suitable health policy is another factor affecting the use of technology in health sector. If the Ministry of Health and Child Welfare happens to improve e-health implementation, health policy should be aligned with technological innovation in medical field.' (Doctor: 3)

This evidence indicates that the government of Zimbabwe lacks a clearly defined policy to support the use of e-health systems in public hospitals. Although the country has an e-health strategy (draft version 2012-2017) that was developed in support of WHO based on the ITU/WHO toolkit (Chikuni 2016), the policy needed to guide e-health development and technological diffusion in public hospitals is limited. There is no clear well-coordinated mechanism in place where e-health implementation is organised. An absence or inadequacy of legislation and policies and liability concerns may hamper the implementation of e-health systems at the organisational and health professional level. Since e-health cannot be implemented in isolation, to foster e-health growth in the public sector an attentive policy needs to be considered. Hence, health policy should compel public hospitals to implement e-health systems (Rodrigues 2008).

\section{Funding}

The Ministry of Health is faced with lack of enough money to equip health institutions with modern technologies because of little budgetary allotment to the health sector by the Ministry of Finance. Most hospitals operate within a budget constraint because there is underfunding. As a result, hospitals are supposed to function with a limited IT budget. According to one doctor:

'It is not easy to implement e-health due to low funding of health sector in Zimbabwe. In turn, it is difficult to apportion [a] lot of money for purchase of ICT resources needed for e-health.' (Doctor: 4) 
'Implementation of electronic health infrastructure is costly and this calls for increased funding in the health sectors.' (Doctor: 19)

This indicates that funding of the health sector determines adoption of e-health (Mugo 2014). According to Scott and Mars (2013), first world countries are able to make significant investments in research to develop information systems that would meet the need of their particular healthcare system. This shows that increased funding in the health sector is strongly correlated with adoption of e-health even in the case of developed countries and this should also be the case for developing countries (Zhang et al. 2015). Owing to low funding of the health sector by the government in third world countries, Omary et al. (2009) argue that it is difficult to allocate much money for acquisition of ICT resources needed in the health sector. Adoption of computerised health infrastructure is costly, and this calls for increased funding in the health sector for various developing countries. In Zimbabwe, the health sector is poorly funded, making it difficult to allocate much money for acquisition of ICT resources needed in the health sector. The Ministry of Health and Child Welfare is usually allocated approximately $\$ 400$ million, which is below the Abuja target and the subSaharan Africa average by $15 \%$ and $11.3 \%$, respectively (UNICEF 2016). Thus, better funding may result in improved implementation of e-health systems and services.

\section{Bureaucracy}

The systems of authority found in the health sector are very stringent and not highly flexible (Simbini 2013). The utilisation of e-health in hospitals is determined by the ministry itself. Hospitals have no right, especially district and central hospitals, to institute e-health systems at their level. There is thus a lack of initiative with regard to e-health from the part of the ministry in terms of medical service delivery. The systems in place, for example, EPOC, DSHI and PMS among others have been introduced by the ministry; however, they have not been cascaded to all other hospitals. The following was noted by one participant:

'Hospitals are not allowed to initiate electronic health systems in their own settings. It is strictly the Ministry of Health and Child Welfare which can do so. This has a negative impact on the rate of diffusion of innovation.' (Doctor: 20)

Thus, a stringent control in the health sector stifles the adoption of technology by public hospitals. Generally, in Zimbabwe, there are stringent laws and regulations regarding the change of procedures in government departments. Hence, public hospitals are not an exception.

\section{Conclusion}

Gradually, e-health solutions are replacing the traditional way of delivering healthcare. The need to implement e-health has attracted the attention of government, health professionals and research institutions in the field of health in both developed and developing countries. Many governments have initiated policies that promote the implementation of e-health at various levels of health facilities. However, the idea of e-health is relatively new to healthcare centres in Zimbabwe. Its application has not been sufficiently addressed. Despite combined efforts by donors, international partners and government in the rolling out of e-health systems, there is partial and non-use of e-health by healthcare professionals (Zhou, Herselman \& Coleman 2016). The state of e-health is low and very unsatisfactory in public healthcare institutions. e-health systems are mainly focused on selected central hospitals, thereby neglecting other hospitals. Thus, its state in public hospitals can be described as nascent. For this reason, the need for guidelines that help promote e-health adoption across the public healthcare institutions cannot be ignored

This study has revealed the factors that influence the implementation of e-health in Zimbabwe public hospitals. The study shows that the success of an e-health system depends on a number of factors. These include government policy, ICT skills and knowledge, ICT and e-health infrastructure, funding, medical facilities, and IT technical support among others. Furthermore, the findings reveal that doctors in public hospitals are facing the same challenges in the implementation of e-health systems. There is a great potential of implementing e-health in Zimbabwe if these factors are taken into consideration. Otherwise, Zimbabwe will continue to lag behind in the implementation of e-health systems in public hospitals.

\section{Acknowledgements}

The authors would like to thank the Ministry of Health Zimbabwe for having awarded them this opportunity to research in their health facilities. The authors are also grateful to Dr Obadiah Moyo from the prestigious Chitungwiza Hospital who was instrumental in making this research a success. His criticisms and contributions were instrumental in realising this work.

\section{Competing interests}

The authors declare that they have no financial or personal relationships that may have inappropriately influenced them in writing this article.

\section{Authors' contributions}

A.C. assisted in giving direction of the research article while S.S.F. did the writing and data collection in hospitals.

\section{References}

Adams, R., Tranfield, D. \& Denyer, D., 2011, 'How can toast be radical? Perceptions of innovations in healthcare', International Journal of Clinical Leadership 17(1), 37-48.

Alberta Health Services, 2010, Health promotion and behavior change theory, Alberta Health Services, Calgary, AB, viewed 12 October 2017, from http://www. screeningforlife.ca/resources/Health\%20Promotion $\% 20$ Evidence/Health $\% 20$ Promotion \%20Evidence/Health\%20Promotion $\% 20$ and $\% 20$ Behaviour $\% 20$ Change\%20Theory.pdf

Ariens, L.F.M., Schussler-Raymakers, F.M.L., Frima, C. \& Flinterman, A., 2013, 'Barriers and facilitators to eHealth use in daily practice: Perspectives of patients and and facilitators to ehealth use in daily practice: Perspectives of patients and
professionals in dermatology', Journal of Medical Internet Research 19, 1-10. https://doi.org/10.2196/jmir.7512 
Bennani, A., Belalia, M. \& Oumlil, R., 2008, 'As a human factor, the attitude of healthcare practitioners is the primary step for the e-health: First outcome of an ongoing study in Morocco', Communications of the IBIMA Journal 3(4), 28-34.

Busagala, L.S.P. \& Kawono, G.C., 2013, 'Underlying challenges of e-health adoption in Tanzania', International Journal of Information and Communication Technology Research 3(1), 34-41.

Caldwell, M. \& Kleppe, I., 2010, 'Early adopters in the diffusion of an HIV/AIDS public health innovation in a developing country', Advances in Consumer Research 37(37), 326-332, viewed 30 October 2017, from http://www.acrwebsite.org/ volumes/15423/volumes/v37/NA-37

Catwell, L. \& Sheikh, A., 2009, 'Evaluating eHealth interventions: The need for continuous systemic evaluation', PLoS Medicine 6(8), 1-6. https://doi.org/ 10.1371/journal.pmed.1000126

Chikuni, D.S., 2016, 'Potential/preparedness of e-health services in Zimbabwe', International Journal of Research in IT and Management 6(1), 26-30.

Crock, E., 2016, 'Access to healthcare services for people living with HIV experiencing homelessness? A literature review', Australian Journal of Advanced Nursing 34(1), $42-51$.

Dehzad, F., Hilhorst, C., De Bie, C. \& Claassen, E., 2014, 'Adopting health apps, what's hindering doctors and patients?', Health 6(1), 2204-2217. https://doi.org/ hindering doctors and patient

Dinev, T., Albano, V., Xu, H., D’Atri, A. \& Hart, P., 2016, 'Individuals' attitudes towards electronic health records: A privacy calculus perspective', in Advances in healthcare informatics and analytics, pp. 19-50, Springer, Cham.

Dünnebeil, S., Sunyaev, A., Blohm, I., Leimeister, J.M. \& Krcmar, H., 2012, 'Determinants of physicians' technology acceptance for e-health in ambulatory care', International Journal of Medical Informatics 81(11), 746-760. https://doi. org/10.1016/j.ijmedinf.2012.02.002

Farzianpour, F., Amirian, S. \& Byravan, R., 2015, 'An investigation on the barriers and facilitators of the implementation of electronic health records (EHR)', Health 7 , 1665-1670. https://doi.org/10.4236/health.2015.712180

Gerber, B.S. \& Eiser, A.R., 2001, 'The patient-physician relationship in the internet age: Future prospects and the research agenda', Journal of Medical Internet Research 3(2), E15. https://doi.org/10.2196/jmir.3.2.e15

Juma, K., Nahason, M., Apollo, W., Gregory, W. \& Patrick, O., 2012, 'Current status of e-health in Kenya and emerging global research trends', International Journal of Information and Communication Technology Research 2(1), 50-54.

Kaerasora, G., 2017, 'Health facilities go paperless', The Sunday Mail, 07 May, 2017 viewed 15 November 2017, from http://www.sundaymail.co.zw/health-facilitiesgo-paperless/

Kart, F., Miao, G. \& Moser, L.E., 2007, 'A distributed e-healthcare system based on the service oriented architecture', in IEEE International Conference on Services Computing, 2007 (SCC 2007), pp. 652-659, 09-13 July 2007, IEEE, pp. 652-659.

Kawulich, B.B., 2004, 'Data analysis techniques in qualitative research', Journal of Research in Education 14(1), 96-113.

Kundi, M., Shah, B., Nawaz, A., Chishti, A.K. \& Qureshi, N., 2013, 'Infrastructural barriers to e-health implementation in developing countries', European Journal of Sustainable Development 2(1), 163-170.

Lam, M.K., Hines, M., Lowe, R., Nagarajan, S., Keep, M., Penman, M. et al., 2016 'Preparedness for eHealth: Health sciences students' knowledge, skills, and confidence', Journal of Information Technology Education: Research 15, 305-334. https://doi.org/10.28945/3523

Lien, A.S.-Y. \& Jiang, Y.-D., 2017, 'Integration of diffusion of innovation theory into diabetes care', Journal of Diabetes Investigation 8(3), 259-260. https://doi. org/10.1111/jdi.12568

Moerman, A.H., Van Houwelingen, C.T.M. \& Kort, H.S.M., 2014, 'An explorative Delphi study to uncover knowledge, attitudes and skills for nurses using eHealth', Master's thesis, Utrecht University.

Mugo, D.M., 2014, 'Determinants of electronic health in developing countries', International Journal of Arts and Commerce 3(3), 49-60.

National Centre for Health Statistics, 2015, National Electronic Health Records Survey: 2015 State and National Electronic Health Record Adoption Summary Tables, viewed 12 July 2017, from https://www.cdc.gov/nchs/data/ahcd/nehrs/2015 nehrs_web_table.pdf

Nielsen, A.V., 2016, 'eHealth activities and hearings aids - A systematic review', in Proceedings of British Academy of Audiology 13th Annual Conference, 10-11 November 2016, viewed 12 October 2017, from https://www.eriksholm.com/-/ media/eriksholm/main/files/publications/2016/presentations/cleveland_ nielsen_baa2016.pdf?la=en

Nzuki, D. \& Mugo, D., 2014, 'Determinants of electronic health in developing countries', International Journal of Arts and Commerce 3(3), 49-60.

Olok, G.T., Yagos, W. \& Ovuga, E., 2015, 'Knowledge and attitudes of doctors towards e-health use in healthcare delivery in government and private hospitals in Northern Uganda: A cross-sectional study', MC Medical Informatics and Decision Making 15(87), 1-10. https://doi.org/10.1186/s12911-015-0209-8
Omary, Z., Lupiana, D., Mtenzi, F. \& Wu, B., 2009, 'Challenges to E-healthcare adoption in developing countries: A case study of Tanzania', in First International Conference on Networked Digital Technologies, 2009 (NDT'09), 28-31 July 2009, IEEE, pp. 201-209.

Öner, N. \& Sertel, Ö., 2015, 'Technology acceptance in health care: An integrative review of predictive factors and intervention programs', Procedia - Social and Behavioral Sciences 195, 1698-1704. https://doi.org/10.1016/j.sbspro.2015. 06.263

Osunyomi, B.D. \& Grobbelaar, S., 2013, 'Integrating eHealth in HIV/AIDS intervention programmes in South Africa', South African Journal of Information Management 17(1), 1-10. https://doi.org/10.4102/sajim.v17i1.623

Qureshi, Q.A. \& Shah, B., 2013, 'Infrastructural barriers to e-Health implementation in developing countries', European Journal of Sustainable Development 2(1), 163-170.

Raingruber, B., 2014, 'Health promotion theories', in Contemporary health promotion in nursing practice, pp. 53-94, viewed 14 October 2017, from http://books. google.co.id/books?id=GeGq5tJIVHYC\&printsec=frontcover\&dq=bonnie+raingru ber+health+promotion+theory+jones+\&+bartlett+learning\&hl=en\&sa=X\&ei=vYR vU6TgAcH-rAfnOIDgBg\&redir_esc $=y \# v=$ onepage \&q\&f=false

Rissanen, M.K., 2014, 'Intensifying innovation adoption in educational eHealth', Science Education International 25(1), 60-67.

Robinson, E., 2008, 'E-health and the Internet: Factors that influence doctors' mediation behaviors with patients', Master's thesis, Georgia State University, viewed 15 November 2017, from https://scholarworks.gsu.edu/communication theses/46

Rodrigues, R.J., 2008, 'Compelling issues for adoption of e-health', in The Commonwealth Ministers Preference, viewed 15 November 2017, from http:// ww.ehealthstrategies.com/files/Commonwealth_MOH_Apr08.pdf

Rogers, E.M., 1995, 'Lessons for guidelines from the diffusion of innovations', The Joint Commission Journal on Quality Improvement 21(7), 324-328.

Ross, J., Stevenson, F., Lau, R. \& Murray, E., 2016, 'Factors that influence the implementation of e-health: A systematic review of systematic reviews (an update)', Implementation Science 11, 146. https://doi.org/10.1186/s13012016-0510-7

Schweitzer, J. \& Synowiec, C., 2010, 'The economics of eHealth', Health 29(2), 235-238.

Scott, R.E. \& Mars, M., 2013, 'Principles and framework for eHealth strategy development', Journal of Medical Internet Research 15(7), e155. https://doi. org/10.2196/jmir.2250

Sementilli, S., Auria, S. \& Mori, A.R., 2007, eHealth strategy and implementation activities in Cyprus, Report in the framework of the eHealth ERA project, viewed 10 December 2017, from http://ehealth-strategies.eu/database/documents/ Cyprus_eHealth-ERA_country_report.pdf

Simbini, T., 2013, Discussion: The impact, opportunities, and challenges ICTS in e-Health, TECHNOMAG, September, viewed 10 November 2017, from http://
www.technomag.co.zw/2013/09/23/discussion-the-impact-opportunities-andchallenges-icts-in-e-health/

Stroetmann, K.A., Artmann, J. \& Stroetmann, V., 2013, 'Developing national eHealth infrastructures - Results and lessons from Europe', AMIA Annual Symposium infrastructures - Results and
Proceedings 2011, 1347-1354.

Tucker, M.T., 2009, 'Application of the diffusion of innovations theory and the health belief model to describe EMR use among Alabama family medicine physicians: A rural and urban analysis', Doctoral dissertation, The University of Alabama, Tuscaloosa, AL, p. 2877 .

UNICEF, 2016, Zimbabwe 2016 health and child care budget brief, viewed 10 December 2017, from https://www.unicef.org/zimbabwe/Zimbabwe_2016 Health_and_Child_Care_Budget_Brief.pdf

Varsi, C., 2016, 'Implementation of eHealth patient - provider communication tools into routine practice facilitators and barriers from the perspectives of patients, middle managers and health care providers', Cecilie Varsi, RN, MSc Faculty of Medicine, University of Oslo.

World Health Organization (WHO), 2016a, Atlas of eHealth country profiles. The use of eHealth in support of universal health coverage, WHO, Geneva, p. 392, viewed 09 October 2017, from www.who.int/\%250Ahttp://scholar.google.com/scholar?hl= en\&btnG=Search\&q=intitle:Atlas+of+eHealth+Country+Profiles $\# 0$

World Health Organization (WHO), 2016b, Global diffusion of eHealth making universal health coverage achievable: Report of the third global survey on eHealth World Health Organization, viewed 07 October 2017, from http://apps.who.int/ iris/bitstream/handle/10665/252529/9789241511780-eng.pdf;jsessionid=BOBE8 A280A0A33E755E9BCCE55CFE0B2? sequence $=1$

Zhang, X., Yu, P., Yan, J. \& Spil, I.T.A.M., 2015, 'Using diffusion of innovation theory to understand the factors impacting patient acceptance and use of consume e-health innovations: A case study in a primary care clinic', BMC Health Services Research 15(1), 71. https://doi.org/10.1186/s12913-015-0726-2

Zhou, M., Herselman, M.E. \& Coleman, A., 2016, 'Investigating factors determining the use of the clinical care module by nurses through the UTAUT model', in The Eighth International Conference on eHealth, Telemedicine, and Social Medicine, eTELEMED 2016, 24-28 April 2016,Venice, Italy, pp. 186-191. 